\title{
Prevalence of ESBL, AmpC and carbapenemase among gram negative bacilli isolated from clinical specimens
}

\author{
Vijaya Doddaiah $^{1}$, Dhanalakshmi Anjaneya ${ }^{2}$ \\ Department of Microbiology, Adichunchanagiri Institute of Medical Sciences, B. G. Nagara, Karnataka, India
}

Email address:

vijayadanand@rediffmail.com (V. Doddaiah), dhans07_adi@yahoo.co.in (D. Anjaneya)

\section{To cite this article:}

Vijaya Doddaiah, Dhanalakshmi Anjaneya. Prevalence of ESBL, AmpC and Carbapenemase among Gram Negative Bacilli Isolated from Clinical Specimens. American Journal of Life Sciences. Vol. 2, No. 2, 2014, pp. 76-81. doi: 10.11648/j.ajls.20140202.17

\begin{abstract}
Background: Antimicrobial resistance is a growing threat worldwide. The predominant mechanisms for resistance to the $\beta$-lactam antibiotics in gram negative bacilli is the production of $\beta$-lactamases. Aim: To determine the prevalence of ESBL, AmpC and carbapenemase production among GNB isolated from various clinical samples. Materials and Methods: A total of 378 GNB isolated were identified and processed for the detection of ESBL, AmpC and Carbapemase production using various methods. Results: Out 378 GNB 197 (52.12\%) showed the presence of one or more $\beta$-lactamases and $181(47.88 \%)$ were negative. $33.86 \%, 14.24 \%$ and $18.25 \%$ showed the presence of ESBL, AmpC and Carbapenemase among the 378 GNB studied. Conclusion: This study highlights the prevalence of ESBL, AmpC and Carbepenemase producing GNB in a rural tertiary care teaching hospital.
\end{abstract}

Keywords: ESBL, AmpC, Carbapenemase, Gram Negative Bacilli

\section{Introduction}

Antimicrobial resistance is a growing threat worldwide. Resistance mechanism have been found for every class of antibiotic agents. The predominant mechanism for resistance to the beta lactam antibiotics in gram negative bacilli (GNB) is the production of extended spectrum $\beta$ lactamase (ESBL), which is responsible for the resistance to the $3^{\text {rd }}$ generation of cephalosporins ${ }^{[1]}$. They cannot hydrolyse cephamycin and are inhibited by clavulanic acid $^{[2]}$. AmpC enzymes are poorly inhibited by clavulanic acid and confer resistance to cephalosporin, $\alpha$-methoxy $\beta$ lactams (cefoxitin, cefotetan) and monobactams. They are susceptible to advanced spectrum cephalosporins (ASCs i.e., cefepime, cefepirome $)^{[3]}$

The introduction of carbapenem into clinical practice represents a great advancement for the treatment of $\beta$ lactam resistant bacteria. Due to their broad spectrum of activity and stability to hydrolysis by most beta lactamases, the carbapenem have been the drug of choice for treatment of infections caused by penicillin or cephalosporin resistant $\mathrm{GNB}^{[4]}$. The metallo $\beta$-lactamase in GNB is becoming a therapeutic challenge, as these enzyme usually possess a broad hydrolysis profile that includes all $\beta$-lactam antibiotics including carbepenems ${ }^{[5]}$. Accurate and timely detection of these resistant mechanisms is very important in deciding the appropriate treatment schedule. Detection of the resistant mechanisms is always a serious challenge to the clinical laboratories ${ }^{[6]}$.

The present study was carried out to determine the resistant phenotypes and the prevalence of co-existence of these resistant mechanisms in gram negative bacilli isolated from various clinical samples.

\section{Materials and Methods}

A prospective study was conducted, from June 2012 to March 2013, in the department of Microbiology of 1000 bedded rural tertiary care teaching hospital, AIMS, B.G.Nagara, Karnataka. Ethical clearance has been obtained from the institution.

A total of 378 GNB isolated from various clinical specimens such as pus (143), urine (134), sputum(43), blood(27), pleural fluid(2), ascitic fluid(2), tracheal aspirate, CSF, stool (1) and vaginal swab(1) were received during study period formed the study group. The isolates were identified by standard techniques ${ }^{[7]}$ GNB isolated were subjected to screening tests for ESBL, AmpC and carbapenemase production as per CLSI guidelines ${ }^{[8]}$. 


\subsection{Screening Test for ESBL, AmpC and Carbapenamase}

Each isolate was swabbed onto Mueller Hinton agar plate (MHA).Amoxicillin Clavulanic acid disc $(20 \mu \mathrm{g}+10 \mu \mathrm{g})$ was placed in the centre of petridish and cefpodoxime $(10 \mu \mathrm{g})$ and ceftazidime $(30 \mu \mathrm{g})$ were placed on either side of amoxyclav disc at a distance of $20 \mathrm{~mm}$. Cefoxitin $(30 \mu \mathrm{g})$ disc was placed at a distance of $20 \mathrm{~mm}$ from cefpodoxime and ceftazidime disc. Meropenem $(10 \mu \mathrm{g})$ disc was also placed in the same plate at a distance of more than $25 \mathrm{~mm}$ from other discs (HI media India). Plates were incubated at $35^{\circ} \mathrm{C}$ for 16 to 18 hours. Organism which showed extension of zone of inhibition of cefpodoxime or ceftazidime towards amoxyclav disc was taken as ESBL screen positive. Blunting of zone of inhibition of ceftazidime towards cefoxitin was taken as AmpC screen positive. Blunting of zone of inhibition of ceftazidime towards amoxyclav was taken as inducible AmpC positive. Zone of inhibition to meropenem disc less than $21 \mathrm{~mm}$ was taken as carbapenemase screen positive.(Fig 1)

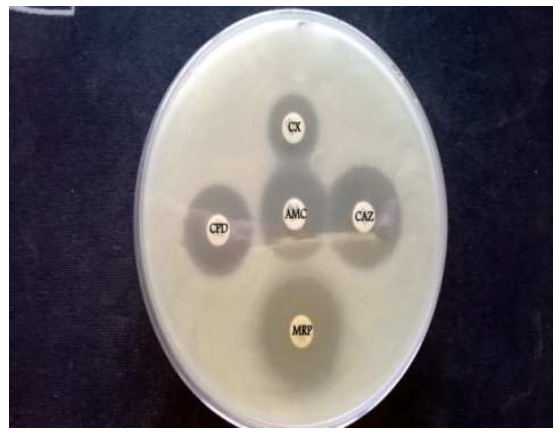

Fig 1. Screening test.

\subsection{Confirmatory Test for ESBL and AmpC}

All GNB were subjected for ESBL and AmpC confirmation.

\subsection{Combination Disc Method}

Each isolate was swabbed on MHA plate. In the upper half of plate, ceftazidime $(30 \mu \mathrm{g})$ disc and ceftazidime + clavulanic disc were placed $30 \mathrm{~mm}$ apart. In the lower half, cefoxitin $(30 \mu \mathrm{g})$ disc and cefoxitin + aminophenyl boronic acid disc $(300 \mu \mathrm{g})$ were placed more than $30 \mathrm{~mm}$ apart. The plates were incubated at $35^{\circ} \mathrm{C}$ for 16 to 18 hours. After incubation $\geq 5 \mathrm{~mm}$ increase in the zone of inhibition of ceftazidime + clavulanic acid disc as compared to ceftazidime disc alone, $\geq 5 \mathrm{~mm}$ increase in the zone of inhibition of cefoxitin plus aminophenyl boronic acid(APBA) disc as compared to cefoxitin alone was taken as ESBL and AmpC positive respectively. Boronic acid derivatives were reported as reversible inhibitors of AmpC enzymes. Boronic acid in combination with clavulanic acid is used for the detection of ESBL among AmpC producing organisms. The use of APBA in disc diffusion testing along with the CLSI described PCT enhances ESBL in the presence of AmpC $\beta$-lactamases. But it fails to detect inducible AmpC. ${ }^{[2]}$ (Fig 2 and Fig 3)

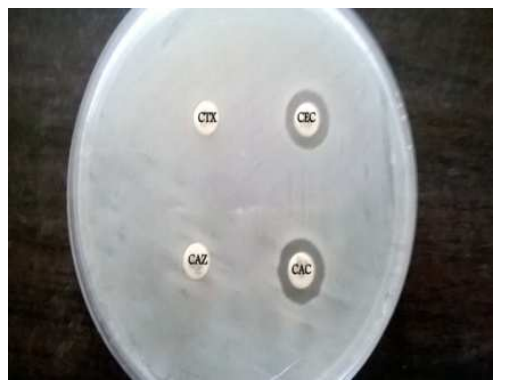

Fig 2. Combination disc method for ESBL confirmation.

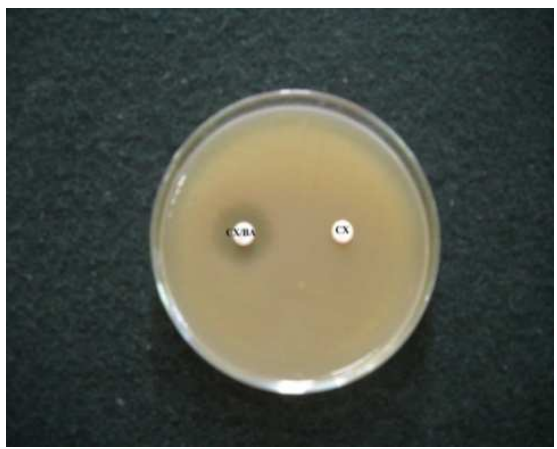

Fig 3. Combination disc method for AmpC confirmation.

\subsection{Confirmatory Test for Ampc}

\subsubsection{AmpC Disc Test (AmpC D test)}

Detection of AmpC mediated resistance in clinical microbiology laboratory poses a problem as CLSI has not yet published guidelines for the detection. Cefoxitin resistant GNB were tested by $\mathrm{AmpC}$ disc test. Lawn culture of Escherichia coli ATCC 25922 was done on MHA. Cefoxitin $(30 \mu \mathrm{g})$ disc was placed on it. Sterile disks $(6 \mathrm{~mm})$ were moistened with sterile saline $(20 \mu \mathrm{l})$ and inoculated with several colonies of the test organism. The inoculated disc was then placed beside cefoxitin disc (almost touching) on the inoculated plate. The plate was incubated at $35^{\circ} \mathrm{C}$ for 16 to 18 hours. Flattening or indentation of the cefoxitin inhibition zone in the vicinity of the test organism disc was taken as positive for AmpC D test, negative test had an undistorted zone. (Fig 4)

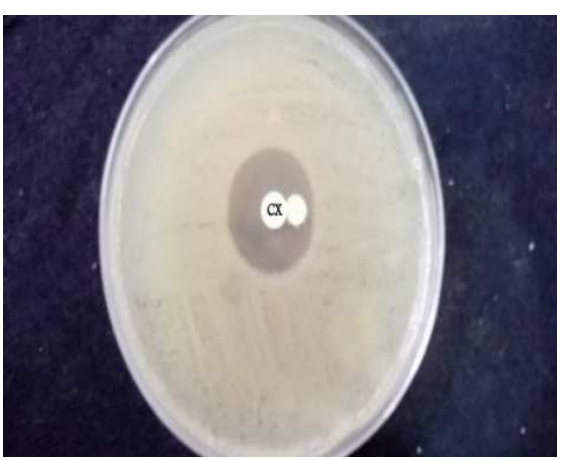

Fig 4. AmpC Disc test for AmpC Confirmation. 


\subsection{Carbapenemase}

GNB, which were screening test positive for carbapenamase (meropenam resistance) were subjected to modified Hodge test(MHT), double disc synergy test (DDS), EDTA combined disc synergy test(CDST-IPM).

\subsubsection{Detection of KPC (Klebsiella Pneumoniae Carbapenemase) Modified and Re-modified Hodge Test (MHT \& RMHT)}

Lawn culture of E.coli ATCC 25922 was done on MHA.Imipenem $(10 \mu \mathrm{g})$ disc and Imipenem plus zinc $(140 \mu \mathrm{g})$ were placed on inoculated plate. Test strains inoculated in a straight line out from the edge of the disc (20 to $25 \mathrm{~mm}$ length). Following incubation, enhancement of growth of indicator strains around imepenem is taken as modified Hodge test positive, imepenem plus zinc disc is taken as re-modified Hodge test positive. Zinc has been known to increase the activity of metallobeta- lactamases. No enhanced growth is considered as negative for carbapenemase production. ( Fig 5, Fig 6)

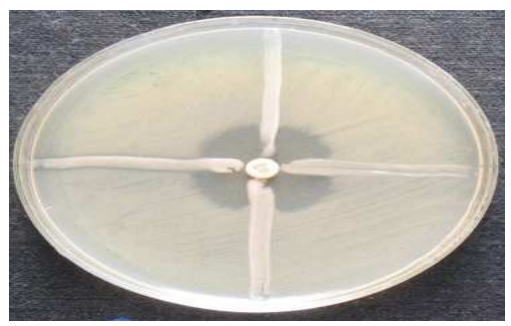

Fig 5. Modified Hodge Test for KPC confirmation.

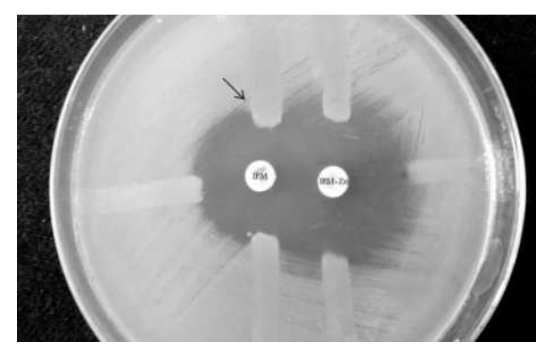

Fig 6. MHT and Remodified Hodge test for KPC confirmation.

\subsection{Detection of MBL (Metallo beta lactamase)}

\subsubsection{Double Disc Synergy Test (DDS) and Combination} Disc Method (EDTA Disc Potentiation Test)

Lawn culture of the test isolate was done on MHA. EDTA plain disc $(750 \mu \mathrm{g})$ was placed in the centre of plate. Imipenem $(10 \mu \mathrm{g})$ disc, imipenem plus zinc disc and imipenem plus EDTA $(750 \mu \mathrm{g})$ were placed at a distance of $20 \mathrm{~mm}$ each from EDTA plain disc. The plates were incubated at $35^{\circ} \mathrm{C}$ for $16-18$ hours. After incubation synergy between imipenam disc and plain EDTA disc and imipenem plus $\mathrm{Zn}$ disc and plain EDTA disc was taken as double disc synergy test positive. $>3 \mathrm{~mm}$ decrease in the zone of inhibition around imepenem plus zinc disc as compared to imipenem disc alone is taken as combination disc positive. Metallobeta-lactamses are zinc dependant. > $7 \mathrm{~mm}$ increase in the zone of inhibition around imepenem plus EDTA disc as compared to imepenem alone was considered as EDTA disc potentiation test positive. EDTA is a chelating agent for metallo beta-lactamases.

\section{Results}

Total number of cases studied- 355. Out of these 378 GNB were isolated (23 samples showed mixed growth of GNB).

Out of 378 GNB $197(52.12 \%)$ showed the presence of one or combination of enzymes. 181(47.61\%) were negative for betalactamases.

Table 1. Occurrence of ESBL, AmpC, carbapenemase among GNB (No. 378).

\begin{tabular}{cc}
\hline Type of $\boldsymbol{\beta}$-lactamase & Positive \\
\hline Only ESBL & 85 \\
Only AmpC & 10 \\
Only carbapenemase & 56 \\
ESBL+AmpC & 33 \\
ESBL+carbapenemase & 3 \\
ESBL+AmpC+carbapenemase & 7 \\
AmpC+carbapenemase & 3 \\
Total positives & $197(52.12 \%)$ \\
\hline
\end{tabular}

Table 2. Organism wise distribution of ESBL, AmpC and carbapenemase.

\begin{tabular}{|c|c|c|c|c|c|c|}
\hline \multirow[t]{2}{*}{ Isolate } & \multicolumn{2}{|c|}{ ESBL } & \multicolumn{2}{|c|}{ AmpC } & \multicolumn{2}{|c|}{ Carbapenemase } \\
\hline & $+\mathrm{ve}$ & $\%$ & $+\mathrm{ve}$ & $\%$ & $+\mathrm{ve}$ & $\%$ \\
\hline $\begin{array}{c}\text { E. Coli } \\
140\end{array}$ & 43 & 30.71 & 15 & 10.7 & 32 & 22.85 \\
\hline $\begin{array}{c}\text { Klebsiella } \\
106\end{array}$ & 53 & 50 & 24 & 22.64 & 17 & 16.03 \\
\hline $\begin{array}{c}\text { Pseudomonas } \\
75\end{array}$ & 14 & 18.66 & 8 & 10.66 & 12 & 16 \\
\hline $\begin{array}{c}\text { Nonfermenter } \\
25\end{array}$ & 11 & 44.00 & 2 & 8.00 & 6 & 24.00 \\
\hline $\begin{array}{c}\text { Citrobacter } \\
12\end{array}$ & 3 & 25 & 1 & 8.33 & 1 & 8.33 \\
\hline $\begin{array}{c}\text { Proteus } \\
12\end{array}$ & 2 & 16.66 & 1 & 8.33 & 1 & 8.33 \\
\hline $\begin{array}{c}\text { Providencia } \\
04\end{array}$ & 1 & 25 & 0 & 0 & 0 & 0 \\
\hline $\begin{array}{c}\text { Enterobacter } \\
04\end{array}$ & 1 & 25 & 2 & 50 & 0 & 0 \\
\hline
\end{tabular}


Table 3. Prevalence of ESBL, AmpC and Carbapenamase among the GNB studied.

\begin{tabular}{|c|c|c|c|c|c|c|c|c|c|c|}
\hline $\begin{array}{c}\text { Isolate No378 } \\
\text { Test }\end{array}$ & $\begin{array}{l}\text { E.coli } \\
\text { No140 }\end{array}$ & $\begin{array}{l}\text { Klebsie } \\
\text { lla } \\
\text { No106 }\end{array}$ & $\begin{array}{l}\text { Pseudo } \\
\text { monas } \\
\text { No75 }\end{array}$ & $\begin{array}{c}\text { Non- } \\
\text { ferment } \\
\text { ers } \\
\text { No25 } \\
\end{array}$ & $\begin{array}{c}\text { Citroba } \\
\text { cter } \\
\text { No12 }\end{array}$ & $\begin{array}{l}\text { Proteus } \\
\text { s } \\
\text { No } 12\end{array}$ & $\begin{array}{l}\text { Provide } \\
\text { ntia } \\
\text { No04 }\end{array}$ & $\begin{array}{c}\text { Enter } \\
\text { obacte } \\
r \\
\text { No } 04 \\
\end{array}$ & $\begin{array}{c}\text { Total } \\
\text { No } 378\end{array}$ & $\begin{array}{l}\text { Percentag } \\
\text { e(+ve) }\end{array}$ \\
\hline ESBL & & & & & & & & & & \\
\hline $\begin{array}{c}\text { Screening test } \& \text { confirmatory } \\
\text { test } \\
\text { Amp C }\end{array}$ & 43 & 53 & 14 & 11 & 3 & 2 & 1 & 1 & 128 & 33.86 \\
\hline Screening test & 15 & 24 & 8 & 2 & 1 & 1 & 0 & 2 & 53 & 14.24 \\
\hline $\mathrm{APBA}+\& \mathrm{AmpC} \mathrm{D}+\mathrm{ve}$ & 4 & 4 & 3 & 1 & 1 & 0 & 0 & 0 & 13 & \\
\hline AmpC D+ve & 1 & 0 & 0 & 0 & 0 & 0 & 0 & 0 & 1 & \\
\hline APBA +ve & 10 & 18 & 4 & 1 & 0 & 1 & 0 & 2 & 36 & \\
\hline Carbapenemase & & & & & & & & & & \\
\hline $\begin{array}{l}\text { Screening test } \\
\text { Positives no } 69\end{array}$ & \multicolumn{10}{|c|}{ Only samples positive for Carbapenemase screening tests, were proceeded for other tests } \\
\hline $\begin{array}{l}\text { Isolates +ve } \\
\text { For KPC }\end{array}$ & 32 & 17 & 12 & 6 & 1 & 1 & 0 & 0 & 69 & 18.25 \\
\hline $\begin{array}{c}\text { Only KPC+ve } \\
(\mathrm{MHT}+\mathrm{ve})\end{array}$ & 0 & 3 & 2 & 1 & 0 & 0 & 0 & 0 & 6 & \\
\hline $\begin{array}{c}\mathrm{KPC}+\text { ve \& MBL+ve } \\
\text { For MBL }\end{array}$ & 3 & 0 & 4 & 1 & 0 & 1 & 0 & 0 & 9 & \\
\hline DDS+ve \& EDTA+ve & 7 & 5 & 6 & 1 & 0 & 0 & 0 & 0 & 19 & \\
\hline EDTA+ve & 19 & 7 & 2 & 2 & 1 & 0 & 0 & 0 & 31 & \\
\hline DDS+ ve & 2 & 0 & 0 & 1 & 0 & 1 & 0 & 0 & 4 & \\
\hline
\end{tabular}

APBA- aminophenyl boronic acid, KPC- Klebsiella pneumoniae carbepenemase, MHT- Modified Hodge Test, MBL- Metallo betalactamases, DDST- Double disk synergy test.

\section{Discussion}

Despite the discovery of ESBL's and AmpC beta lactamases at least a decade ago, there remains a low level of awareness of their importance and many clinical laboratories have problem in detecting ESBL and AmpC beta lactamases. Confusion exists about the importance of these resistance mechanisms, optimal test methods and appropriate reporting conventions. Failure to detect these enzymes has contributed to their uncontrolled spread and sometimes to therapeutic failure ${ }^{[9]}$. The newer beta lactamases like ESBL, AmpC and carbapenemase has emerged as a cause of antibiotic resistance among the GNB worldwide in the recent years ${ }^{[6]}$.

In the present study ESBL's were found in $34.04 \%$ of the isolates which is compared with other studies in table $4^{\text {[9- }}$ 13]. The existing data show a wide variation in the prevalence of these mechanisms from region to region or even from hospital to hospital in the same region ${ }^{[14]}$.

Maximum number of ESBL and AmpC was found among Klebsiella Spp (50\%), and Enterobacter (50\%) respectively, which is compared with other studies (table no 2 and 4).

In the present study, inducible AmpC was found in $3(5.66 \%$ ) isolates (E.coli 2, Klebsiella Spp 1), whereas Shoorashetty has reported $14(7 \%)$.

APBA test for the detection of AmpC in GNB is more sensitive (92.45\%) compared to AmpC disk test alone. Several methods of phenotypic detection of AmpC beta lactamases are described; however, these methods are labour intensive and subjective, lack sensitivity and/or specificity and cannot be adopted on a routine basis.

In the present study $18.25 \%$ of isolates were carbapenemase positive which is compared with the other studies in table 4.

Table 4. ESBL, AmpC and Carbapenamase in GNB as reported by various workers.

\begin{tabular}{|c|c|c|c|}
\hline Study & Prevalence \% & E.coli \% & Klebsiella \% \\
\hline \multicolumn{4}{|l|}{ ESBL } \\
\hline $\begin{array}{c}\text { Present study } \\
2013\end{array}$ & 30.86 & 30.71 & 50 \\
\hline Singhal 2005 & 64 & 62.7 & 73 \\
\hline Shoora shetty & 68.86 & 80.95 & 67.08 \\
\hline Uma devi 2011 & 69 & 81.06 & 74.07 \\
\hline $\begin{array}{c}\text { Chitra valsan } \\
2013\end{array}$ & 60 & - & - \\
\hline \multicolumn{4}{|l|}{$\mathrm{AmpC}$} \\
\hline $\begin{array}{c}\text { Present study } \\
2013\end{array}$ & 14.02 & 10.7 & 22.64 \\
\hline $\begin{array}{c}\text { Shoorashetty } \\
2011\end{array}$ & 33.5 & 33.33 & 37.97 \\
\hline Singhal 2005 & 8 & 6.97 & 6.18 \\
\hline $\begin{array}{c}\text { Chitravalsan } \\
2013\end{array}$ & 10 & - & - \\
\hline \multicolumn{4}{|l|}{ Carbapenamase } \\
\hline $\begin{array}{c}\text { Present study } \\
2013\end{array}$ & 18.25 & 22.85 & 16.03 \\
\hline Pandya 2011 & 6 & 2.87 & 7.26 \\
\hline $\begin{array}{c}\text { Chitravalsan } \\
2013\end{array}$ & 12.6 & - & -- \\
\hline $\begin{array}{c}\text { Shoorastetty } \\
2011\end{array}$ & 0 & - & - \\
\hline Rai 2011 & 1.38 & 50 & 32.35 \\
\hline Dutta 2012 & 7.87 & & \\
\hline Shanthi 2012 & 53.24 & & \\
\hline
\end{tabular}


In the present study, 46 isolates showed combination of 2 or 3 enzymes. Out of this ESBL coexisted with AmpC in $33(71.3 \%)$, ESBL with carbapenemase in 3(6.52\%), ESBL with both AmpC and carbapenemase in 7(15.21\%), AmpC with carbapenemase in $3(6.52 \%)$. The presence of ESBL and AmpC beta lactamases in a single isolate reduces the effectiveness of beta lactam inhibitor combination.

27.96\% of ESBL coexisted with AmpC. $3.40 \%$ of ESBL coexisted with carbapenemase. The present data show wide variation in the prevalence of beta lactamase from region to region or even from hospital to hospital in the same region $^{[14]}$.

Carbapenemase was found in $18.25 \%$. Among the MBL positive, $50 \%$ were E.Coli, $32.35 \%$ Klebsiella, $7.84 \%$ Citrobacter, $6.86 \%$ Enterobacter, $2.94 \%$ Proteus. Maximum number was found in Nonfermeters $31.57 \%$, followed by E.coli $22.85 \%$, Klebsiella species $16.03 \%$, Pseudomonas aeruginosa 16\%, Citrobacter spp and Proteus spp $8.33 \%$ each. KPC alone was found in 6 $(8.69 \%)$, MBL in $54(78.26 \%)$ out of 69 GNB studied. MBL and KPC were found in $9(13.04 \%)$ isolates. In Pandya's study highest carbapenemase isolates were detected in Pseudomonas $9.92 \%$, followed by Klebsiella (7.26\%), Acinetobacter Spp (7.14\%), and E.coli (2.87\%).

Of the 69 carbapenamase producing isolates, $4.34 \%$ were with ESBL,with AmpC in $4.34 \%$ and with ESBL +AmpC in $10.14 \%$. This has also been reported by others ${ }^{[6,15]}$.The present study indicates there is high level of co-expression of various resistance mechanisms among the $\mathrm{GNB}^{[15]}$.

DDST-IPM, is most sensitive method in the detection of MBL production in GNB when compared to DDST (table 2). Detection of beta-lactamases in GNB by phenotypic method is rapid, technically simple compared to molecular techniques. Carbapenemase have emerged and spread, leading to carbapenem resistance. The only treatment option that remains is the potentially toxic polymyxin B and colistin ${ }^{[16]}$. Hence it is necessary to know their incidence in the clinical isolates of the hospital, so as to formulate a policy of empirical therapy to high risk patients. Failure to identify them may lead to inappropriate therapy, treatment failure and may result in increased mortality. This is preliminary study done to bring awareness among the clinicians about prevalence of beta lactamases in this hospital.

\section{Conclusion}

Drug resistant pathogens are increasing rapidly and becoming major problem in the area of infectious diseases. Early detection of changing resistance patterns is very important in preventing the dissemination of resistant bacteria and modifying the treatment strategies.

\section{Acknowledgement}

This study was supported by Adichunchanagiri Shikshana Trust Bangalore. Authors are grateful to president Poojya guru Sri Nirmalananda Swamiji, trustees Dr. Devaraj D and Dr. Sunil M. Our special thanks to Principal Dr. Shivramu MG and Superintendent Dr.Manohar TM, AIMS, B.G. Nagara, for encouragement and support during the study.

\section{References}

[1] Umadevi S, Kanhakumari G, Joseph NM, Kumar S, Eaow JM, Atephen S, Singh UK. Prevalence and antimicrobial susceptibility pattern of ESBL producing gram negative bacilli. J Clin Diag Res 2011; 5(2): 236-239.

[2] Shoorashetty RM, Nagarathnamma T, Prathibha J. Comparison of the boronic acid disk potentiation test and cefepime-clavulanic acid method for the detection of ESBL among AmpC-producing Enterobacteroaceae. Indian J Med Microbiol 2011; 29 (3) :297-30.

[3] Jacoby GA. AmpC $\beta$-Lactamases. Clin Microbiol Rev 2009;22:161-82.

[4] Jesudason MV, Kandathil AL, Balaji V.Comparison of two methods to detect carabapenemase and matallo- $\beta$-lactamase production in clinical isolates. Indian $J$ Med Res 2005;121:780-3

[5] Galani I, Rekatsina PD, Hatzaki D, Plachouras D, Souli M, Giamarellou H. Evaluation of different laboratory tests for the detection of metallo $\beta$-lactamase production in Enterobacteriaceae. J Antimicrob Chemother2008;61:54853.

[6] Valsan C, Chinnan JP, Sathiavathy KA. Phenotypic detection of $B$-lactamases in enterobacreriaceae using a 12disk procedure. J Acad Clin Microbiol 2013;15(1):7-10.

[7] Collee JG, Fraser AG, Marmion BP, Simmons A. Mackie \& McCartney Practical Medical Microbiology. $14^{\text {th }}$ ed. Edinburgh (UK): Churchill Livingston;1999

[8] Clinical and Laboratory Standards. Performance Standards for Antimicrobial susceptibility Testing; Twentieth Informational Supplement. CLSI Document M 100-S20, Wayne, PA: CLSI,Wayne,PA,USA,2010.

[9] Singhal S, Mathur T, Khan S, Upadhyay DJ, Chugh S, Gaind, Rattan A. Evaluation of Methods for AmpC BetaLactamase in gram negative clinical isolates from tertiary care hospitals. Indian J Med Microbiol. 2005;23(2): 120124.

[10] Nirav P, Pandya, Sweta B, Prajapati, Sanjay J, Mehta et al. Evalution of various methods for detection of metallo- $\beta$ lactamase (MBL) production in Gram negative bacilli.Int $J$ Biol Med Res 2011;2(3):775-777 .

[11] Rai S, Manchanda V, Singh NP, Kaur IR. Zine-dependent carbepenemases in clinical isolates of family Enerobacteriaceae. Indian J Med Microbiol 2011; 29(3):275-9.

[12] Datta P, Gupta V, Garg S, Chander J. Phenotipic method for differentiation of carbapenemases in Enterobacteriaceae; study from North India. Indian $J$ Pathol Microbiol 2012;55:157-60 
[13] Shanthi M, Sekar U, Arunagiri K, Sekar B. Detection of AmpC genes encoding for beta-lactamases in Escherchia coli and Klebsiella pneumonia. Indian J Med Microbiol 2012;30:290-5.

[14] Babypadmini S, Appalaraju B. Extended-spectrum betalactamases in urinary isolates of coli and Klebsiella pneumonia- Prevalence and susceptibility in a tertiary care hospital. Indian J Med Microbiol 2004;22:172-4.
[15] Paul Schrekenberger Escherichia. Phenotypic Detection of $\beta$-Lactamase resistance in gram negative bacilli. Testing and Interpretation Guide. Available from: http://www.scacm.org/phenotypic Detection Antibiotic resistance_rev5.pdf (Last reviewed on 2012 Fseb 21)

[16] Behera B,Mathur P,Das A,Kapil A,Sharma V. An evaluation of four phenotypic techniques for detection of mettalo bête lactamase producing Pseudomonas aeruginosa. Indian $J$ Med Microbiol 2008;26(3):233-37. 